\title{
The girl from the Church of the Sacrament: a case of congenital syphilis in XVIII century Lisbon
}

\author{
Sheila Mendonça de Souza ${ }^{+}$, Sonia Codinha*, Eugénia Cunha*
}

\begin{abstract}
Departamento de Endemias Samuel Pessoa, Escola Nacional de Saúde Pública Sergio Arouca-Fiocruz, Rua Leopoldo Bulhões 1480, 21041-210 Rio de Janeiro, RJ, Brasil *Departamento de Antropologia, Faculdade de Ciências e Tecnologia, Universidade de Coimbra, Coimbra, Portugal
\end{abstract}

Syphilis is a sexually or congenitally transmitted infectious disease with an impact on the health of human populations that has undergone important cycles in different countries and periods of history. Its presence was first diagnosed in Europe in the late XIV century. In Portugal, although there are various written records of the infection in the last centuries, there are rare references to it in archeological findings (mummified bodies are also rare in Portugal). The current study describes a probable case of congenital syphilis in an 18-month-old girl buried in the Church of the Sacrament in Lisbon. Her body, dating to the XVIII century, was found mummified together with dozens of others, still not studied. Symmetrical periostitis of the long bones, osteitis, metaphyseal lesions, left knee articular, and epiphyseal destruction, and a rarefied lesion with a radiological appearance compatible with Wimberger's sign all point to a diagnosis of congenital syphilis. The diagnosis of this severe form of the infection, possibly related to the cause of death in this upper-class girl, calls attention to the disease's presence in XVIII century Lisbon and is consistent with the intense mobilization at the time in relation to the risks posed by so-called heredosyphilis. It is the first case of congenital syphilis in a child reported in archeological findings in Portugal, and can be correlated with other cases in skeletons of adults buried in cemeteries in Lisbon (in the XVI to XVIII centuries) and Coimbra (XIX century). Finally, this finding highlights the need to study the entire series of mummified bodies in the Church of the Sacrament in order to compare the paleopathological findings and existing historical documents on syphilis, so as to expand the paleoepidemiological knowledge of this infection in XVIII century Lisbon.

Key words: paleopathology - syphilis - mummification - bioarcheology - XVIII century

Seventy partially or totally mummified bodies were found in the XVIII century crypt under the altar at the Church of the Sacrament in Lisbon, Portugal. This crypt was rebuilt after the complete destruction of the original building by the earthquake that struck the city in 1755 , causing widespread destruction (Almeida 1975). Judging by the types of coffins and the clothing in which the bodies were buried, they belong to middle and upper class individuals, but although the study of these mortal remains is just beginning, it has already been determined that they include several clergy and even a bishop. Although many cases of natural mummification have been described in Europe, particularly in Italy (Aufderheide 2003), this type of finding is still rare in Portugal. Despite its extreme importance, anthropological analysis of the bodies at the Church of the Sacrament has begun only recently.

The current article presents the results of a collaborative study between the Research Group in Paleopathology and Paleoparasitology at Fiocruz and the Department of Anthropology at the University of Coimbra. This is the analysis of a child's body, particularly relevant because it shows bone and dental lesions consistent with a diagnosis of congenital syphilis. In addition to paleobiological

\footnotetext{
Financial support: Capes, Fundação Totta

${ }^{+}$Corresponding author: sferraz@ensp.fiocruz.br

Received 20 July 2006

Accepted 16 October 2006
}

and paleopathological aspects, the paper also provides a summary description of the funeral accoutrements, preparation of the body, and its state of preservation. Given the paucity of information on syphilis from material found in Portuguese archeological sites, knowledge of this infection and its history in the country is based almost exclusively on written documents, with scare findings in human bones from medical collections and historical cemeteries, as reported by one of the authors in a previous article (Codinha 2002). Although the series from the Church of the Sacrament is not representative of the overall Lisboan population, but only part of its elite, these mummies may provide important health information for this historical period, social class, and location, and research on this series of human remains should be continued. In the case of this premature death, the diagnostic hypothesis of congenital syphilis signals an epidemiological situation that is consistent with reports from the literature (Quetel 1986), the direct knowledge of which can now be expanded.

\section{Syphilis}

Venereal syphilis was reported for the first time by Cumano in 1495 (Quetel 1986). From the beginning, the infection has been associated with sexual transmission and a series of prejudices that have persisted to the present day. The study of syphilis has thus been associated with a curious dispute, in which the responsibility for contagion and the role of spreading the disease have frequently been attributed to neighboring countries or groups with whom there has been contact. 
During the XVI and XVII centuries, in many countries and particularly in England and Germany, syphilis was referred to as the morbus gallicus or French disease. However, the French did not accept this epithet passively, and in France it was referred to as the Italian disease. To the Persians it was the Turkish disease. According to the Polish it was the German pox. Meanwhile in Russia it was the Polish disease. Among the Japanese it was known as the Portuguese disease, in a clear reference to its existence in Portugal. However for the Portuguese it was known as the Castilian disease. The Flemish and Dutch knew it as the Spanish pox. But in Spain, where in fact the first cases had been recorded in the XV century, it was attributed to contagion to which Colombus' crew had been exposed in the New World. Thus its origin was not only controversial, due to the natural difficulty in establishing the history of any infectious disease, but also confused with the need to escape the stigma of the sexual vices and sins associated with it.

Different types of treponematoses have been known to different peoples of the world and have been distributed on different continents in various eras, from historical times back to the remotest periods of pre-history. However, venereal syphilis appears to be more recent and is the only type specifically adapted to sexual transmission. According to some authors it is associated with changes in cultural habits such as the use of clothing (Cockburn 1963). For some time, evolutionist theories supported by Hacket (1963) appeared to provide adequate models for understanding the emergence and behavior of this infection over time. However, according to authors like Brothwell (2005), retrospective analysis of efforts in the last forty decades of specialized studies, and data collected by the fields of history, epidemiology, and paleopathology have still not succeeded in answering the questions posed by syphilis and its origins. The understanding of this human disease involves complex evolutionary processes in the host-parasite relationship, and much remains to be investigated to achieve a fuller understanding.

The first explanation for the appearance of syphilis in XV century Europe was the so-called Colombian theory, which attributed the disease to returning sailors who had been infected by Native Americans in the New World. The first publication, by Ruy Dias de Isla from 1510 to 1520 , reports on the treatment of various cases of a new and frightening disease. Later confirmed by Gonzalo Hernandez de Ovivedo y Valdez, the same disease was diagnosed among Spanish mercenaries who included some of Colombus' crew at the service of the French Armada, under Charles VIII. The appearance of this disease, apparently new to Europe, led Girolamo Fracastoro to write a poem in 1530 about a wayward swineherd named Syphilis who suffered from this ill. After the impact of the first European cases, venereal syphilis became clinically less severe and was even considered increasingly benign (Quetél 1986). During the XVI century, curiosity, motivation towards poetry, and a certain indulgence characterized society's behavior towards syphilis.

The XVII century witnessed a certain silence in relation to syphilis, and most of what was written about it adopted a moralistic discourse. But congenital syphilis was already well known at the time and was considered a menace, including the risk of death or degeneration in children. The disease was treated in general hospitals, but venereal patients were not isolated from others. Subject to social segregation and even penalties, syphilis patients were treated mainly with mercury salts (Quetél 1986). Such mercury-based medicines had been used at least since the XV century and were believed to expel the "poison" from bodily humors by provoking intense salivation, vomiting, diarrhea, and sweating. Inhalation, rubbing on bare skin, and ingestion were various forms of administering mercury that were used until the early XX century, including in Brazil (Rodrigues 2005). The most frequent complications of this treatment were intoxication, colitis, and dermatosis. Use of mercury preparations could lead to rapid dehydration and even death. Even so, mercury was especially recommended for children, who were believed to respond well to this treatment. One of its sequelae was the formation of dental erosions parallel to the gum line (Wilcox 1950).

Although venereal syphilis had been described in great detail since the 15 th century, for a long time it was confused with other sexually transmitted diseases like chancre and gonorrhea. Progress in medical knowledge allowed an understanding of its specificity and severity as well as its differentiation from other forms of treponematosis, like yaws and bejel. In practice, the disease was largely characterized by extended, silent evolution. Tertiary symptoms are late, and even in the absence of treatment they would be limited to fewer than $20 \%$ of patients today. This means that after the clinically exuberant primary and secondary phases of the infection, the disease allowed life to go back to normal, partially explaining the unconcerned behavior described in the European population in relation to this hardly lethal infection, an attitude Carrara (1996) refers to as "lay indifference". In addition, since the life expectancy of human populations was relatively short until the XVIII century, many patients probably died before presenting severe tertiary sequelae.

In the XVIII century, the moralistic discourse on the disease was attenuated and replaced by a rationalism that assumed the risk of contracting syphilis as part of love life. Meanwhile, with the legalization of dissecting cadavers, knowledge concerning cardiac and neurological syphilitic lesions increased. The XVIII century also witnessed widespread quackery, promising various cures for the infection. In different European countries, including France and Spain, there was a growing discussion of so-called heredosyphilis and the consequences of transmitting the disease to children. Admitting different forms of contagion that might occur at conception and during intrauterine life and childbirth, medical authorities focused special attention on wet nurses, who they believed were responsible for most cases of infant contagion. Statistics from this period in France indicate a 90\% mortality rate among children born of mothers with syphilis, and specialized institutions in some cities, like Paris, began attempting to reduce the mortality and effects of congenital syphilis through hospitalization (Quetél 1986).

Although little is known about the disease in Portugal 
based on archeology, the disease is believed to have reached major proportions there in historical times, consistent with Lisbon as one of the most important European ports from the XV to XVIII centuries. The nature and intensity of trade and exploratory activities by Portugal, in addition to a background of intense social changes, also help explain the emergence of venereal syphilis in Portuguese territory, as elsewhere.

Eighteenth-century documents from Portugal such as Arte da Enfermagem (The Art of Nursing), from 1741 (Graça 2005), mention "terrible and shameful syphilis" as one of the diseases of the time. Syphilis, cholera, and yellow fever are presented as "common diseases of the times" in Volume V of História de Portugal (History of Portugal), which focuses on the XVIII century. Garret confirms the introduction of mercury-based medicines to treat syphilis in Portugal, beginning in the 18th century. This and other testimony show syphilis as a relevant health issue in 18thcentury Lisbon.

In the late XIX century, prophylactic and educational measures, the policing of customs, and treatment based on the attempt to eliminate germs became public policies, including in countries like Brazil. These measures were accompanied by hygienist campaigns aimed at disciplining customs and controlling activities like prostitution. The discourse of protection extended to the upper classes, since syphilis affected everyone democratically (Carrara 1996, Rodrigues 2005). By this time, arsenic salts (including Salvarsan) were already being used to treat the disease.

The origin of syphilis is still controversial, but evidence suggests it existed in the Old World prior to the discovery of America (Powell \& Cook 2005). For example, much of what was called venereal leprosy or congenital leprosy was more characteristic of syphilis than Hansen disease, beginning with its contagiousness. Jewish health writings dating to 3000 B.C. already described a venereal disease with the characteristics of treponematosis, different from chancre and gonorrhea and treated with mercury. But it was not until the mid-XIX century that paleopathology began to focus on syphilis, both in prehistorical America and the Old World. Scientists who either supported or challenged the Colombian theory began to search for signs of syphilis in mummified or skeletonized human remains. One major difficulty in this investigation was always the similarity between the bony lesions of tertiary syphilis and those of other treponematoses like yaws and bejel, whose transmission is neither sexual nor congenital. Another difficulty is that the bony lesions in most cases of syphilis are not pathognomonic, and are similar to those found in other disease states. Thus, the study of congenital cases of the disease was always considered crucial for proving the existence of the venereal form of the infection in human populations. Therefore, the study of congenital cases combined with a paleoepidemiological approach (Buikstra \& Cook 1992, Souza et al. 2003) is of great paleopathological interest.

We now know that venereal syphilis is a treponematosis that belongs to the same family as yaws, pinta, and endemic syphilis. Syphilis is contagious and caused by the bacteria T. pallidum pallidum, whose only host is man (Beeson \& McDermott 1971), and is transmitted from person to person through contact with the mucosa or wounded skin. The bacteria can also cross the placenta, whereby it is transmitted to the fetus during gestation. Once inside the body, it spreads through the bloodstream causing lesions in bones, the central nervous system, and other sites.

Congenital infection occurs in some $80 \%$ of infected pregnant women (King \& Nicol 1969), principally when the maternal disease is still in the primary or secondary stages, and occurs more frequently in young mothers. Infected women are prone to late-stage abortion and stillbirth, but the infants may also develop more active infection several months after birth. The period with the greatest risk of death is between one and two years of age, and even after remission of symptoms, the late effects of gumma remain (Beeson \& McDermott 1971). In the months after birth, intrauterine infection has morphological and pathophysiological consequences, causing typical sequelae. Disorders of chondral osteogenesis (Robins 1974), manifested as perichondritis, chondritis, osteitis, and periostitis, are the most frequent lesions. The latter give rise to so-called "saber shins". Hepatosplenomegaly can occur very early, and the newborn infant often has a greatly enlarged liver and thus increased abdominal volume. Reddish skin lesions and vesicles similar to those of secondary syphilis can occur, usually several weeks after birth. Other clinical characteristics include hair loss, principally in the occipital area, senile facies, and a café au lait type skin color (King \& Nicol 1969). Permanent signs left by the disease are defective teeth (Hutchinson's incisors and Moon's molars), interstitial keratitis, central nervous system abnormalities, hydrocephalus, and "saddle nose" (Wilcox 1950).

\section{The mummy and its follow-up and preservation}

The mummified child in the Church of the Sacrament was found in a coffin made of pink-painted boards, lined on the inside with white cotton fabric and measuring 80 $\mathrm{cm} \times 35 \mathrm{~cm} \times 30 \mathrm{~cm}$. It consisted of a lid and base connected by metal clasps, and the upper part was covered with white lace and tatting. Damage from insects, stains, and the loosening of some boards can be observed. The mummified body was found lying inside the closed coffin, which was the correct size for the child. A greatly deteriorated cushion left the head in a slightly elevated position. The cushion consisted of fabric and yellowish plant matter, partially adhered to the skull, and which should not be confused with hair.

In order to preserve the clothing for future specialized studies, we chose not to remove or cut them or remove the pins, and the body was examined on the parts that could be exposed by pulling aside the cloth. In some parts such as the backside of the body the fabric had deteriorated. On the front, a $3 \mathrm{~cm}$ area of basting was undone to allow opening the clothing and complete exposure of the legs and abdomen. The body was totally clothed, in the traditional Christian position in dorsal decubitus with the arms folded over the abdomen and the fingers intertwined in the praying position (Fig. 1). Under the hands was a straight metal rod, heavily deteriorated, adhered to the 


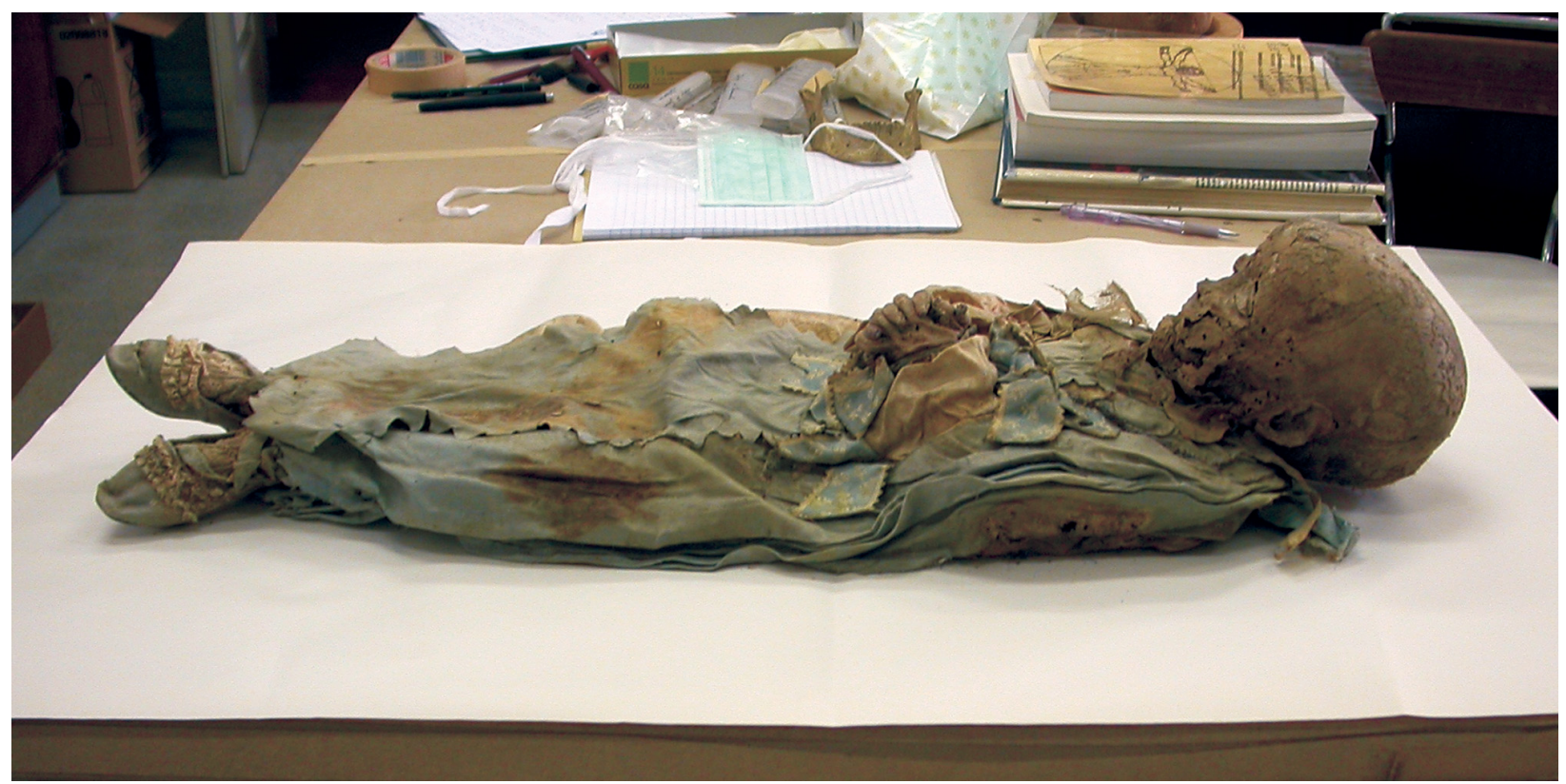

Fig. 1: the mummified body of the XVIII century girl found in the Church of Sacramento, Lisbon.

clothing, and reaching the left shoulder. This indicates the presence of an artificial branch that probably contained flowers, of the same kind widely used in Portugal and called "saudade". The hands and branch were tied with a wide blue ribbon with white flowers and tatting. Twenty-three pins, heavily oxidated with verdigris, appear on different parts of the clothing, and some of them were located by radiography. The body is slightly curved to the left, with the lower left limb fixed rigidly in abduction, observed by the slight inclination of the foot. The left arm is slightly higher than the right, and the chest is rotated slightly to the left.

Bits of cloth are adhered to the chin and eyebrows. Various places on the head show mesh marks on the skin, indicating that a piece of clothing or veil was placed over the face. The outer ears are well-preserved, with the upper part firmly adhered to the skull, unlike the lower part which is separated from it, suggesting that the ears were pressed by some type of cap or headband at the time of burial. The white dress, extending down to the heels, is sewn in front and has long, ballooned sleeves. A rectangular piece of blue fabric with pinked edges is attached to the front of the dress by two pins. A full cape made of the same fabric, gathered and hemmed with a white silk ribbon, is tied at the neck with a bow. Both the dress and cape appear to be made of the same kind of fabric. Underneath the dress is a white slip with a brown floral pattern. Lace hose, relatively well preserved over the feet but undone on the legs and hips, have threads extending over the pelvis, signaling their limit at the waist. The blue cloth shoes with kid leather soles and two horizontal pleated white ribbon appliqués are worn on the feet and tied to the legs with crisscrossed blue ribbons.

Direct examination of the body showed that the state of preservation is relatively good, but not homogeneous, with holes in the skin suggesting the effect of insects. Although no pupae or larvae were found, part of the body was disaggregated in a granulous sediment suggesting action by termites. Part of the degradation probably occurred after the coffin was initially found and opened and the body handled. As generally occurs with mummified bodies (Aufderheide 2003), the part resting on the coffin was more deteriorated, having completely lost the clothing, skin, and part of the muscles and dorsal and thoracic bones. In the preserved portion, the skin was silky, dry, light-colored, and scarcely parchment-like, with little retraction, remaining flexible enough to bend without difficulty. The subcutaneous, periosteal, and muscle tissues and fasciae can be defined and can still be dissected according to their anatomical planes. The skeleton is completely preserved and in anatomical order, attached by some of the articular ligaments.

The head lost part of the epidermis, with the bony surface showing through in some places, and there is no hair on the skull. The face is relatively well preserved, the eyelids are partially closed, the nose maintains its shape, the lips are half-open, and the teeth are articulated. The ventral portion of the thorax and abdomen is preserved. The skin on the arms and hands is intact, and the fingernails are partially present. The skin on the right thigh and lower leg is preserved. However, on the left side the lateral and posterior skin has numerous holes and a brown stain around an extensive destroyed area, with the bones showing through. Although the knee bones are apart, they remain attached by a tendon. Adhered to the same tendon, between the tibia and femur, there is a small amorphous bone fragment that could be the remodeled proximal epiphysis of the tibia. There are no signs of postmortem destruction of the metaphyseal surfaces or those of other bony parts of this knee, reinforcing the hypoth- 
esis that the observed destruction, including that of the skin, was mainly pathological rather than taphonomic.

The hands and some parts of the head have purplish marks. A red circle some $6 \mathrm{~mm}$ in diameter can still be seen on the left cheek. On the opposite side there is an identical coloring on the skin, possibly the remains of make-up used for the funeral. The right knee has a crimson red line some $5 \mathrm{~mm} \times 1 \mathrm{~mm}$, as if drawn with a colored pencil. Above the left knee there is a similar colored stain some $10 \mathrm{~mm}$ long producing a diffuse stain on both the external and internal side of the damaged skin on the thigh.

\section{Bioarcheological analysis}

The methodology employed for studying this mummy included detailed visual examination followed by full-body $\mathrm{X}$-rays from the antero-posterior angle and in the anatomical support position in which the body mummified. The latter examination was performed at the Imaging Services Department of the University Hospital of Coimbra. Image analysis was followed by a new detailed inspection of all the exposed skin, palpation of the bones and other underlying structures, and dissections. The following were dissected: parts of the abdominal cavity, opening the anterior wall on the left side; right forearm Fig. 2), opening a window in the skin on the dorsal aspect; and an area on the scalp, on the left frontal region. It was possible to perform a detailed examination of the left leg, especially the bones (Figs 3,4), through preexisting openings in the skin. The differential diagnosis used a comparative analysis of the lesions and abnormalities and was based on the specialized literature in both the field of paleopathology (Hacket 1986, Aufderheide \& RodriguesMartins 1998, Ortner \& Putschar 1998, Powell \& Cook 2005) and clinical medicine (Wilcox 1950, McLachall 1951, Chaves 1961, King \& Nicol 1969, Beenson \& McDermott 1971, Robins 1974, Resnick 1996).

Visual inspection allowed confirming that the child was a female based on the genitalia, since the vulva is well preserved with the labia majora and genital orifice. Examination of the skull bones and teeth showed partial clo-

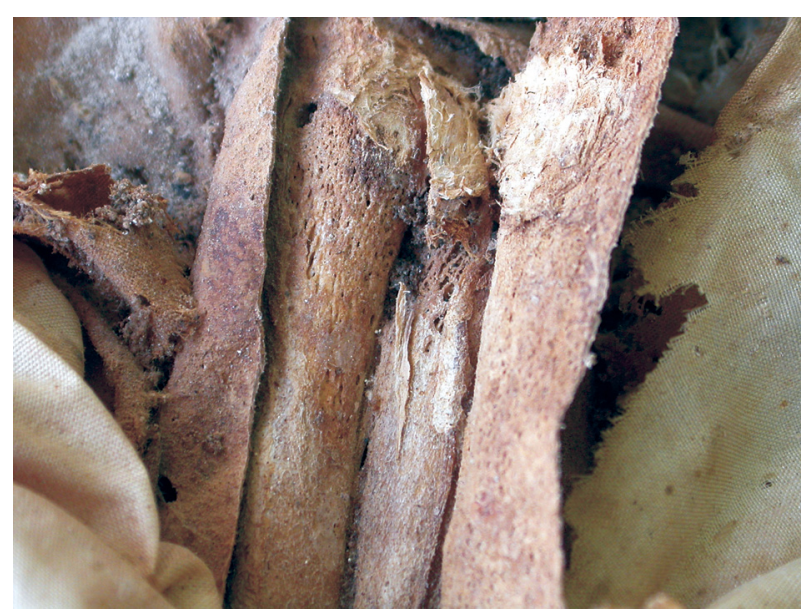

Fig. 2: dissected left forearm of the mummy, exposing the diaphysis of radius and cubitus with periosteal neoformation.

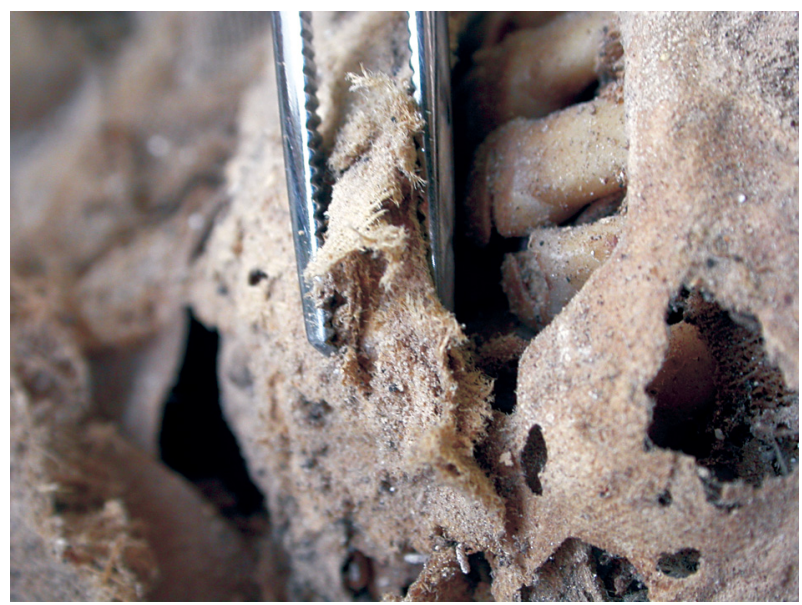

Fig. 3: incisor teeth showing erosion consistent with sequellae of the use of mercury salts.

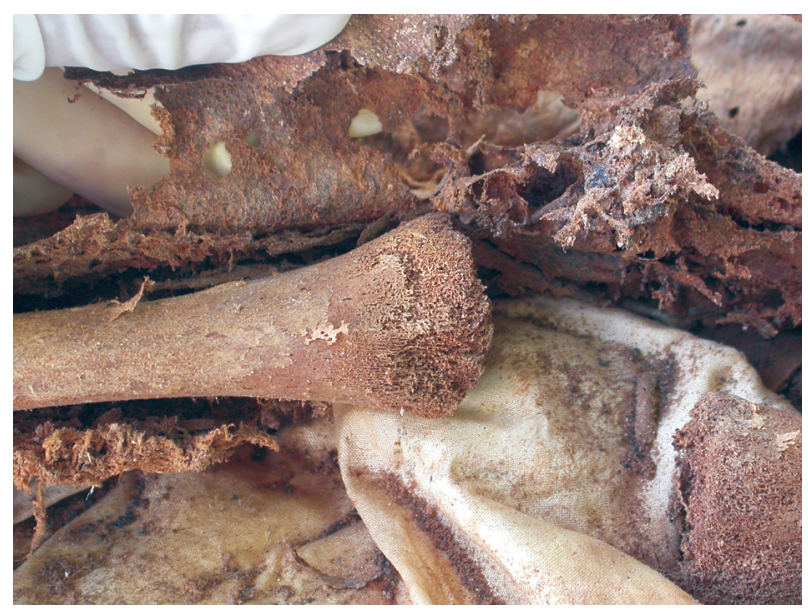

Fig. 4: bones of the left knee seen through the rotten skin. The proximal metaphysis of the tibia is partially destroyed and the black small bone fragment on the upper part of the immage is probably the distal epiphysis of the femur.

sure of the anterior fontanelle, whose diameter is reduced by half $(2 \mathrm{~cm} \times 2 \mathrm{~cm})$. The tooth development stage shows all the deciduous teeth, with the incisors and molars, with their roots completely formed, confirming the age of approximately 18 months, also consistent with the limb osteogenesis (Ubelaker 1978).

The skull shows slightly porotic areas on the outer plate, suggesting inflammatory foci in the periosteum, in addition to symmetrical punctiform lesions on both parietal bones, next to the saggital suture and in the obelial area, perhaps an initial process of porotic hyperostosis. On the left frontal bone, a thick grooved line parallel to the upper rim of the orbit and measuring some $3 \mathrm{~cm}$ shows bone neoformation, indicating a process already undergoing resolution, perhaps an injury to the facial skin. In facial profile the frontal bone shows a pronounced curvature. Through the half-open mouth, the left lateral upper incisor shows excavated, irregular, and elongated destruction on the buccal aspect of the crown, parallel 


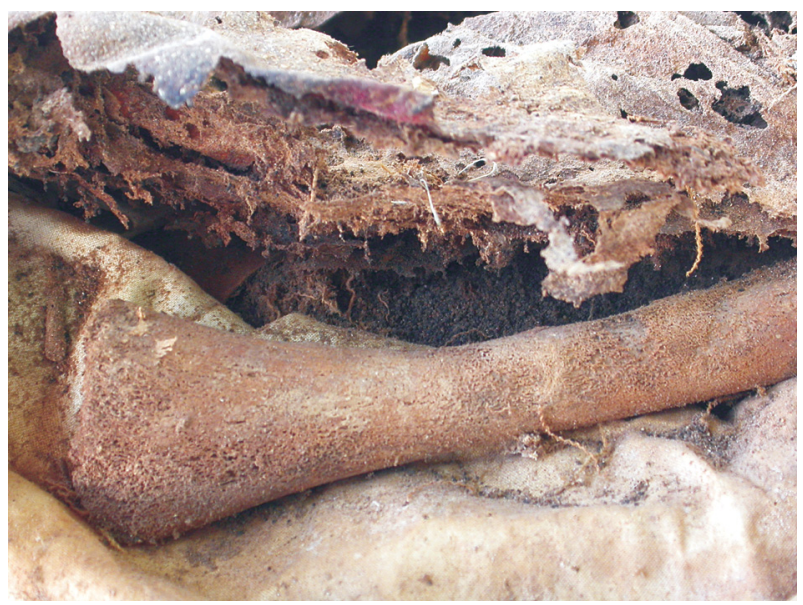

Fig. 5: left femur showing proliferative periostitis along the anterior diaphysis.

to the gum line (Fig. 5). The lesion is similar to an elongated erosion or caries with rounded, irregular, and darkened edges, similar to the marks left by the use of mercury salts (Powel \& Cook 2005).

The X-rays show the mummified skin line around the entire body, except for the destroyed area of the left thigh and part of the trunk on the same side. The loss of skin contour corresponds to the presence of a dense area in the form of a stain, along the lateral portion of the left leg. Coincidentally, the outline of the pins fastening the dress accompanies the stain, suggesting that the latter demarcated a deformity already existing in the body when it was dressed. This hypothesis is supported by the slight inclination of the body to the right and the abduction of the left thigh, which were set in an asymmetrical position. The ribs have a normal radiological appearance, but the thorax is bell-shaped, clearly opening downward (Fig. 6), perhaps caused by abdominal expansion in life. No radiological alterations were found in the pelvis.

Radiological examination of the limbs shows overlap-

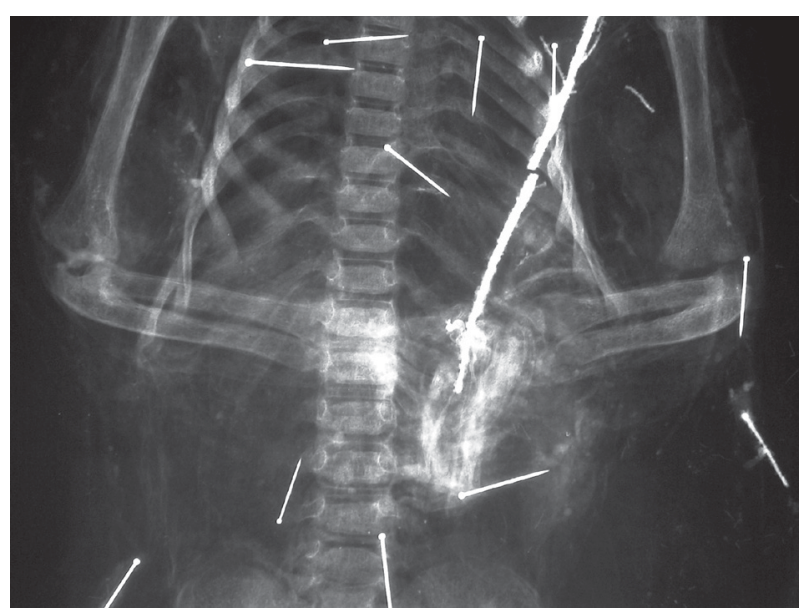

Fig 6: radiographic image of the bell-shaped thoracic cage of the mummified girl. Notice the metal pins and rod on dressings. ping laminar neoformation in the diaphyses of the long bones, characterizing the condition known as "bone within bone". The metaphyses show radioluscent areas surrounded by bone reaction (Fig. 7). The proximal epiphysis and metaphysis of the left humerus (Fig. 8) and femur (Fig. 9) are deformed by intense bone remodeling, and the cartilage growth line is erased. Next to the proximal metaphysis of the right humerus there is a radiodense line and a rounded area with less density, surrounded by a halo of bone neoformation. On the distal extremity of the same side there are two other radiolucent areas surrounded by radiodense areas. On the left side there are modeling alterations located some $2 \mathrm{~cm}$ from the bone extremity, and it was not possible to distinguish between the epiphysis and the cartilage growth space. The bone's diameter is widened and irregular, with poorly defined limits in the cortical area, while the cancellous bone shows disorganized trabeculation. The pattern suggests a symmetrical and systemic process extending to the four limbs and ac-

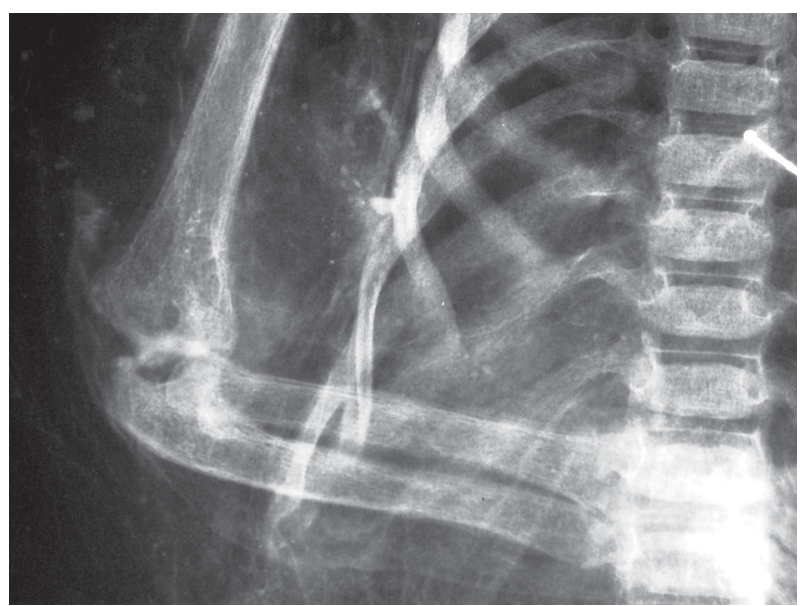

Fig. 7: detail of the right forearm showing the enlarged diameter of the bones and the superimposed ossified periosteal layers at the diaphyisis.

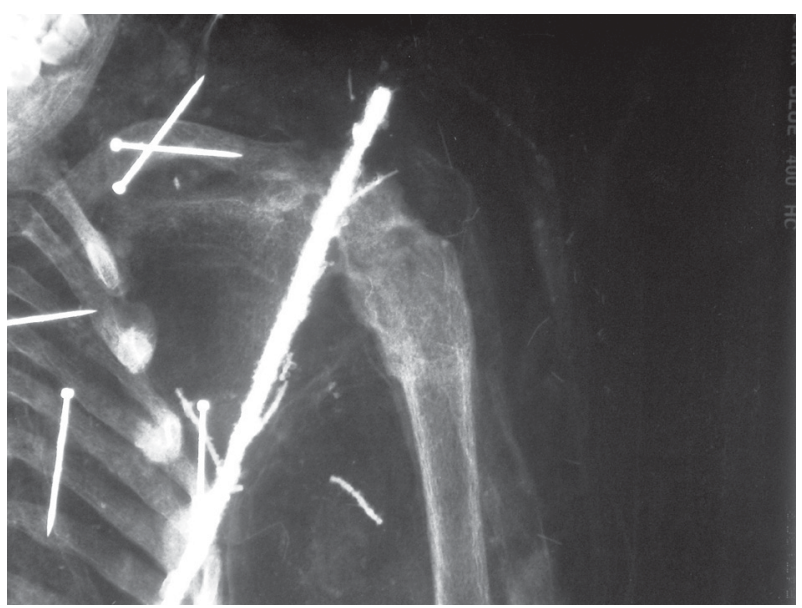

Fig. 8: radiography of the left humerus showing the remodeled proximal extremity where radioluscent areas are surrounded by reactional bone. 


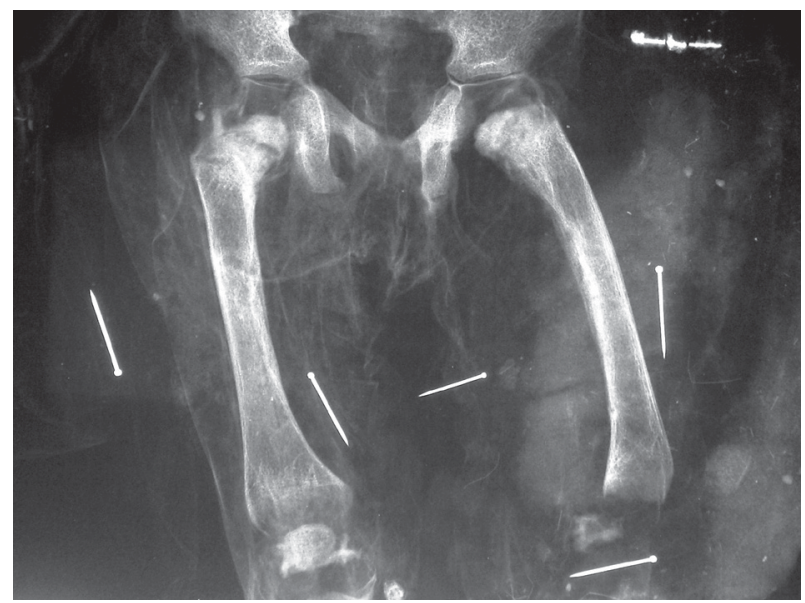

Fig. 9: radiography of the lower limbs showing irregular bone neoformation on the femoral diaphysis, destruction of the proximal portion of the left femur, and extensive destruction of the left knee.

companied by reactional activity. The forearm metaphyses are overlapping and cannot be well visualized due to the fixation of the hands, but the irregular and symmetrical bone proliferation in the diaphyses of the four bones is consistent with periostitis. The cortical layers and the bones themselves are thicker than expected, so that the diameter of the forearm bones is similar to that of the humerus.

Direct examination of the bones through the window dissected in the right forearm (Fig. 2) allowed confirming the presence of neoformed tissue, deposited irregularly on the external cortical surface of the radius and ulna, as suggested by the X-ray.

The right femur has a radiodense line on the proximal metaphysis and diaphyseal alterations similar to those found in the upper limbs, although less pronounced, while the distal epyphysis is normal. The right knee shows an increase in the intrarticular space, radiodense deposits along the bony contours, and periostitis of the tibial diaphysis. Palpation of the right leg showed the bone structures fixed in normal anatomical position. The left femur is fixed in lateral rotation, with altered modeling of its proximal extremity. Examination did not show articular cartilage, and the femoral metaphysis has an irregular contour. The diaphyseal alterations, both radiologically and in anatomopathological examination (Fig. 4), are similar to those on the right side, with bone neoformation distributed irregularly on the diaphyseal cortical surface. In place of the knee joint there is a large space between the femur and the tibia, and it was not possible to identify the epiphyses. In their place one observes the presence of an irregularly shaped bone fragment whose structure, suggested by the radiological density, is that of remodeled bone. Examination of the joint area shows that this fragment is adhered to a tendon that extends from the thigh to the lower leg, so it may be the tibial epiphysis adhered to the tendon of the quadriceps. The fact that part of the muscle and tendon structures is preserved maintains the bones oriented and in relative position, despite the epiphyseal destruction. The left tibia also has periostitis lesions in the cortical layer of the diaphysis and shows an area of medial destruction in the metaphysic, visible on radiography and confirmed by direct examination, consistent with the so-called Wimberger's sign (Wimberger 1925), pathognomonic of congenital syphilis. The left knee metaphyses has their contour preserved, with no postmortem destruction. The tibia and fibula are articulated normally to each other and to the left foot.

\section{Discussion}

Upon initial examination, this body's preservation appears to have been facilitated by the conditions in the environment where it was buried, especially the fact that the crypt is a dry, cold place with little oxygen and no sunlight and protected from outside moisture by the building's limestone and marble structure. Numerous cases of natural preservation have been described under similar conditions in Europe, most especially in Italy (Aufderheide 2003). Desiccation in a stable environment, in so-called "underground, rock-lined chambers", appears to have been the main factor for preservation in these cases, although techniques may have been used to prepare the bodies for interment.

Some practices for preparing bodies, favoring their preservation after death, became more frequent from the XVIII century onward and became almost a fashion, especially among the well-to-do classes. These included careful washing of the body and application of oils, perfumes, camphor plugs for the natural orifices, and application of chemical products. Preparing the body for more prolonged visitation before burial was a common practice in Europe, and from 1750 onward evisceration was frequent in Portugal, associated with incisions that allowed draining the body fluids. Injections of scented oils, together with red dyes, as observed on the girl's face, were used to improve the cadaver's appearance (Rodrigues 1990). In the case of this child, no signs of incisions were found on the skin, although the destruction of some parts of the body may have erased such vestiges. The skin's flexibility suggests that liniments or oils were used, which would have helped preserve its elasticity. The nasal orifices are dilated, consistent with the use of camphor plugs, which are volatile and would soon disappear completely. Although the crypt's conditions are favorable, preservation of this large group of mummified bodies and their historical period lead to the hypothesis that some such practice was used on the bodies, which should be elucidated by further study. In small bodies such as that of the girl, dehydration would be even quicker (Aufderheide \& Rodrigues-Martín 1998).

Bioanthropological examination of this child showed systemic pathological signs suggestive of an infection, confirmed by the anatomopathological and radiological tests. Periostitis, osteitis, and chondritis or symmetrical metaphysitis are consistent with the description of congenital syphilis. The bell-shaped thorax, consistent with increased hepatic and splenic volume, and the bilateral knee arthritis are other signs of this disease. The accentuated frontal curvature further reinforces this hypothesis. 
Congenital syphilis is an infection transmitted from mother to fetus, generally between the XVI and XVIII weeks of intrauterine life. Current statistics allow estimating that $80 \%$ of untreated infected mothers transmit the disease, and a large portion of the infected children, like the one in the present case, die before reaching two years of age. Many of the manifestations of congenital syphilis occur as bony lesions due to the tropism of T. pallidum pallidum for skeletal tissues during the active growth phase. Metaphysitis normally occurs after birth and has been described in more than $70 \%$ of infected individuals, most frequently affecting the knees, ankles, wrists, and shoulders; the multiple symmetric lesions on the proximal extremities of the tibias are characteristic, as observed in this girl. Later, around two years of age, or earlier in more severe cases, the diaphyses are affected by characteristic laminar periostitis, when successive layers of bone are formed, also observed in X-rays and on the exposed surface of some bones after dissecting or laying back the skin. Congenital syphilis has also been associated with complete separation of the epiphysis due to inflammation, as appears to have been the case with this child, especially on the left side, where we observed a process of advanced articular and epiphyseal destruction, in addition to the Wimberger's sign, considered pathognomonic of syphilis (Wimberger 1925, Ortner \& Putchard 1984, Resnick 1996, Aufderheide \& Rodriguez-Martin 1998). Although the most severe phase of chondritis occurs during the first year of life, the effects extend for a variable length of time (King \& Nicol 1969, Robbins 1974), so it is still possible to see some slight metaphyseal alterations in this 18-month-old child. Diaphyseal periostitis is a later response to the infection, manifesting as cortical thickening and increased bone diameters, which were also seen in this case. The set of bone and joint alterations is thus consistent with the diagnosis and natural evolution of the pathological processes occurring in early congenital syphilis in children (McLachall 1951, King \& Nicol 1969).

The radiological silhouette of one of the permanent central incisors shows a marked notch on the occlusal rim, suggestive of dental malformation (Hutchinson 1858). Finally, the presence of an incisor with an erosion parallel to the gums on the buccal aspect also reinforces this diagnosis, since it is consistent with the use of mercury salts, as witnessed by the literature cited previously, including for XVIII century Portugal. In addition to being consistent with the treatment used at that time for syphilis, this observation supports the hypothesis on the use of a medication whose effects may have not only precipitated the child's death, but also helped dehydrate the body.

The series of lesions in this case also suggests that over the course of her short life, this girl suffered acute bone and joint pain, especially when moved. Clinical signs of pain when moving children whose bone extremities and joints show accentuated chronic inflammation are characteristic of congenital syphilis and could have occurred with this girl, given the extent of her bone and joint lesions. Considering the extensive lesion in her left knee, even affecting the skin, it is also possible that part of the destroyed area was associated with the joint lesion and perhaps an ulcerated wound, a complication also described in such cases (King \& Nicol 1969).

Although the evidence as a whole clearly points to congenital syphilis, one needs to rule out other disease conditions. Rickets, scurvy, and leukemia are the main differential diagnoses, given that the principal evidence in this case is found in the bones and joints. These conditions can produce periostitis, bony deformities, and metaphyseal and epiphyseal fractures.

Leukemia, although relatively more rare and seen in older children (3-4 years of age), can produce diaphyseal lesions of the periostitis type and very similar bony alterations, with frequent metaphyseal involvement (Resnick 1996, Beenson \& McDermott 1972). Producing alterations in different organs and tissues, leukemia causes acute bone pain due to arthritis, hemorrhage, and bone necrosis. Periosteal nodules in the diaphyses, cortical thinning due to bone marrow proliferation, and pathological fractures can occur. In the present case, although the metaphyseal processes might be confused, the age and diaphyseal appearance are not consistent with leukemia, and no other typical signs of leukemia were observed, such as generalized hemorrhages.

Rickets has always been compared to syphilis, and both diagnoses are still discussed in orthopedic treatises (Chaves 1961), although rickets tends to occur in older children. Bone deformities in rickets are associated with physical effort that fractures the malformed bones, and thus the principal lesions occur in the lower limbs and in individuals that move more freely. Thickening of bones in the lower limbs is more marked on the concave side, which gives way to the body's weight, while in syphilis, as in this girl, the thickening is caused by accumulated layers of periostitis resulting from the inflammatory reaction and can even be more exuberant in the arms than in the legs. Meanwhile, in rickets and under compression, the long bones suffer a veritable curvature of the diaphyses, while in syphilis the curved appearance results from the accumulation of layers of periosteum on the outer cortical surface, as in this child, with no true deviation of the long bone's axis. Unlike syphilis, rickets is associated with cortical thinning and bone rarefaction, neither of which was observed in the present case. Meanwhile the metaphyses, when affected by rickets, become swollen, thickened, broadened, sloped, and with a typical beak-like or dome-shaped ending, which is not the case in this child's $\mathrm{X}$-rays. Finally, although a funnel-shaped thorax is typical of rickets, it is accompanied by the so-called "rachitic rosary" and abnormal curvature of the spinal column, which were not observed here.

Scurvy is a vitamin-deficiency disease with long evolution, and at least four months of major dietary deficiency with a total absence of vitamin $\mathrm{C}$ is necessary to initiate the clinical picture, which would be highly unlikely given this girl's socioeconomic status and place of residence. In addition, this deficiency does not occur during breastfeeding and has been described only six to twelve months after weaning. Its most striking characteristic in bones involves sub-periosteal hemorrhages with ossifications located in the cortical bone, found throughout the skeleton but most frequently in the distal femur, proxi- 
mal humerus, and skull, none of which was observed in this child. Although there are discrete lesions suggestive of porosis on the cranial surface, they are not consistent with the hemorrhagic periosteal lifting found in scurvy. Although the metaphyseal lesions may have a similar appearance, in scurvy there would not be the symmetrical periostitis observed in this child. Scurvy is also frequently associated with tooth loss and the formation of petechiae and cutaneous hematomas, due to the same hemorrhagic processes that can occur in other tissues. These anatomoclinical characteristics and the necessary conditions for the development of this vitamin-deficiency disorder were not found in this girl either, so the diagnosis of scurvy was ruled out.

Previous findings of treponematoses in archeological material or ancient collections from Portugal are quite scarce, and are considered rare in the country's paleopathological case series. In the second Chapel of the Epistle in the Church of the Carmelite Convent, a right femur and fibula probably from the same individual, dated between 1500 and $1800 \mathrm{AD}$, show lesions consistent with syphilis (Lopes \& Cardoso 2000). A XIX century skull found in the Collection of Identified Skulls from Schools of Medicine at the Department of Anthropology, University of Coimbra, shows caries sica lesions (Santos 2004). Two complete skeletons removed from the ruins of the Church of the Carmelite Convent in Lisbon show symmetrical lesions with extensive periosteal lesions in the long bones and star-shaped skull lesions characteristic of treponematoses, probably syphilis, as proposed by Codinha (2002).

Throughout Europe, including Portugal, as the medical literature indicates, syphilis was a public health problem in the 18th century. Both physicians and the lay public knew of the disease and its consequences for pregnant women and congenital manifestations. The finding of this child showing lesions consistent with congenital syphilis and its treatment has enriched this documentation and confirms other paleopathological findings, still relatively scarce, in Portugal.

\section{Conclusion}

This case proved to be extremely interesting not only because the individual is well preserved, and because of the artifacts and chronology associated with the child, but especially due to the diagnosis of congenital syphilis. In fact, although there are historical references to syphilis outbreaks in Portugal, the disease had been diagnosed only rarely through archeological records (Codinha 2002, Lopes \& Cardoso 2000), with both cases from Lisbon and dating between 1500 and $1800 \mathrm{AD}$.

The current study describes the mummified body of an 18-month-old girl buried in the crypt at the Church of the Sacrament in Lisbon, in the XVIII century. In this child, a series of bony, articular, and dental lesions is consistent with the diagnosis of congenital syphilis, and a dental sequela is consistent with the mercury treatment used for syphilis at the time, especially in children.

The diagnosis of this case and its correlation with other paleopathological findings, as well as with the literature references for Europe, confirm the existence of this disease in the higher social classes and emphasizes the need for more detailed investigation, especially in the other mummified bodies in the same crypt, given the possibility of performing a complete paleoepidemiological study and learning more about the manifestations and consequences of this disease in that society and during that historical period.

\section{ACKNOWLEDGMENTS}

To the collaboration by the University Hospital of Coimbra, through its Imaging Services Department, which conducted the necessary exams for this study.

\section{REFERENCES}

Almeida F 1975. Monumentos e Edificios Notáveis de Lisboa, Junta Distrital de Lisboa, Lisboa.

Aufderheide AC 2003. The Scientific Study of Mummies, Cambridge University Press, Cambridge.

Aufderheide AC, Rodriguez-Martín C 1998. The Cambridge Encyclopaedia of Human Paleopathology, Cambridge University Press, Cambridge, $478 \mathrm{pp}$.

Benson PB, McDermott W 1971. Tratado de Medicina Interna de Cecil-Loeb. T. I, II, Interamericana, Mexico, 2080 pp.

Brothwell DR 2005. North America treponematosis against the bigger world picture. In ML Powell, DC Cook (eds), The Mith of Syphilis, University Press of Florida, Gainesville, p. 480-496.

Buikstra JE, Cook DC 1992. Paleopatologia. In AJG de Araújo, LF Ferreira (eds), Paleopatologia \& Paleoepidemiologia. Estudos Multidisciplinares, ENSP, Rio de Janeiro, p. 4186.

Codinha S 2002. Two cases of venereal syphilis from the cemetery of the Igreja do Convento do Carmo (Lisboa). Antrop Port 19: 29-40.

Carrara S 1996. Tributo a Venus? A Luta Contra a Sifilis no Brasil, da Passagem do Século aos Anos 40, Fiocruz, Rio de Janeiro, 327 pp.

Chaves DA 1961. Lições de Clínica Ortopédica, V. I, II., Edição do autor, Rio de Janeiro, 996 pp.

Cockburn TA 1963. The Evolution and Eradication of Infectious Diseases, Johns Hopkins Press, Baltimore.

Graça L 2005. Apresentação, a arte da enfermagem no sec XVIII. In Pe FD de Santiago, Postila Religiosa e Arte dos Enfermeiros I - VI, Acalá, Lisboa.

Hacket CJ 1963. On the origin of the human treponematoses. Bull WHO 29: 7-41.

Hutchinson J 1858. Report on the effects of infantile syphilis in marring the development of the teeth. Trans Pathol Soc London 9: 449-455.

King A, Nicol C 1969. Venereal Disease, Balliére Tindall \& Cassell, London, 319 pp.

Lopes LA, Cardoso H 2000. Possível caso de sífilis em fémur e tíbia direitos de um indivíduo proveniente do carneiro da segunda capela da epístola do convento do Carmo de Lisboa (Sécs. XVI-XIX?), Contributos das ciências e das tecnologias para a arqueologia da Península Ibérica. Actas do $3^{\circ}$ Congresso de Arqueologia Peninsular ADECAP, Vila Real 1999, Porto, p. 459-463 
McLachan EW 1951. Handbook of Diagnosis and Treatment of Venereal Diseases, E \& S Livingstone, Bristol, 368 pp.

Ortner DJ, Putschar W 1997. Identification of Pathological Conditions in Human Skeletal Remains, Smithsonian Contributions to anthropology \#28, Washington DC, 488pp.

Powell ML, Cook DC 2005. The Myth of Syphilis. The Natural History of Treponematosis in North America, University of Florida, Gainesville.

Quétel C 1986. Le Mal de Naples. Histoire de la Syphilis, Seghers, Paris, 348 pp.

Resnick D 1996. Bone and Joint Imaging, Saunders, New York.

Robins SL 1974. Pathological Basis of Diseases, Saunders, Philadelphia.

Rodrigues RCL 2005. Mãe de Família: Discurso Profilático Contra a Sifilis, Rio de Janeiro, 1878-1989, MSc Thesis, Escola Nacional de Saúde Pública Sérgio Arouca, Rio de Janeiro, $98 \mathrm{pp}$.

Rodrigues T 1990. Crises de Mortalidade em Lisboa. Séculos XVI e XVII, Horizonte, Lisboa.
Santos AL 2000. A Skeletal Picture of Tuberculosis. Macroscopic, Radiological and Historical Evidence from the Coimbra Identified Skeletal Collection, PhD Thesis, Departmento de Antropologia da Universidade de Coimbra, Coimbra, 244 pp.

Santos C 2004. A case of venereal syphilis in a young adult male from Ribeira de Santarém (Portugal). Abstracts of the 15th European Meeting of the Paleopathology Association, University of Durhan, Durhan.

Souza SMFM de, Carvalho DM, Lessa A 2003. Paleoepidemiology: Is there a case to answer? Mem Inst Oswaldo Cruz 98 (Suppl. I): 21-28.

Wilcox RR 1950. A Textbook of Venereal Diseases, W Heinchmann, London, 439 pp.

Weimberger H 1925. Klinisch-Radiologische Diagnostik von Rachitis, Skorbut und Lues Congenita in Kindesalter. Ergebnisse der inneren Medizin und Kinderheilkunde 28: 264-370.

Ybelaker D 1989. Human Skeletal Remains: Excavation, Analysis and Interpretation, 2nd ed., Smithsonian Institution, Washington DC. 